\title{
Papers
}

\section{Outcome of long stay psychiatric patients resettled in the community: prospective cohort study}

Noam Trieman, Julian Leff, Gyles Glover

\begin{abstract}
Objective To examine the outcome of a population of long stay psychiatric patients resettled in the community.

Design Prospective study with 5 year follow up. Setting Over 140 residential settings in north London.

Subjects 670 long stay patients from two London hospitals (Friern and Claybury) discharged to the community from 1985 to 1993.

Main outcome measures Continuity and quality of residential care, readmission to hospital, mortality, crime, and vagrancy.

Results Of the 523 patients who survived the 5 year follow up period, $469(89.6 \%)$ were living in the community by the end of follow up, $310(59.2 \%)$ in their original community placement. A third (210) of all patients were readmitted at least once. Crime and homelessness presented few problems. Standardised mortality ratios for the group were comparable with those reported for similar populations.

Conclusions When carefully planned and adequately resourced, community care for long stay psychiatric patients is beneficial to most individuals and has minimal detrimental effects on society.
\end{abstract}

\section{Introduction}

The government has decided to review the "care in the community" policy after several high profile murder cases involving mentally ill patients. In his foreword to Modernising Mental Health Services, the secretary of state for health stated that "community care has failed, because while it improved the care of many who were mentally ill, it left far too many walking the streets, often at risk to themselves or a nuisance to others. A small but significant minority have been a threat to themselves or others." Our study provides evidence from research into the outcomes of former patients of psychiatric hospitals, which argues for a balanced judgment as to the failure or success of the longstanding policy known as community care.

In 1983, the North East Thames Regional Health Authority decided to close two of its largest psychiatric hospitals-Friern and Claybury. At that time the patient population of each hospital had already decreased to a third of their peak capacity but still comprised over 800 long stay patients.
Resettling large numbers of residual patients in the region raised questions about the programme's feasibility, the potential benefits for patients, the public's safety, and costs. With only the precedents of a few reprovision programmes in the early 1980s and virtually no evidence from systematic research, the plan was a bold venture and several mental health professionals disputed its wisdom. ${ }^{1}$

In 1985, the Team for the Assessment of Psychiatric Services (TAPS) was established with funding from the North East Thames Regional Health Authority and later the Department of Health to evaluate the closure of psychiatric hospitals. After obtaining ethical approval from all district health authorities involved in the reprovision programme, the team launched a major prospective study to assess the social and clinical outcomes of the patients after their resettlement in the community. We present the outcome for these people 13 years after the research project was started.

\section{Subjects and methods}

\section{Subjects}

The study included patients who had been in hospital for over a year (long stay) and who, if aged over 65 years, did not suffer from dementia. A baseline survey conducted by the team in Friern hospital and Claybury hospital in 1985 identified 770 individuals who met these criteria. $^{2}$

As long as the acute services remained at both hospitals, new patients continued to accumulate. Those who stayed for over a year then became part of the sample ("new long stay" patients). Although these patients inflated the census population, others included in the baseline survey died in hospital before their scheduled discharge.

We excluded two groups of long stay patients from Friern hospital: 57 patients who moved to other hospitals during the reprovision programme, and 64 patients ("difficult to place") who were relocated in specialised facilities from 1992 to $1993 .^{3}{ }^{4}$

Our study sample (670 patients) comprised all long stay patients discharged from Friern hospital during its 8 year reprovision programme, and 200 patients from Claybury hospital who were resettled in the community from 1985 to 1990 before its reprovision programme was postponed by the North East Thames Regional Health Authority because of insufficient funds.

\author{
Department of \\ Psychiatry and \\ Behavioural \\ Sciences, Royal Free \\ and University \\ College Medical \\ College Medical \\ School, London \\ NW3 2PF \\ Noam Trieman, \\ senior lecturer \\ Julian Leff, \\ professor of social and \\ cultural psychiatry \\ Section of \\ Community \\ Psychiatry, Institute \\ of Psychiatry, De \\ Crespigny Park, \\ London SE5 8AF \\ Gyles Glover, \\ senior lecturer \\ Correspondence to: \\ Dr Trieman \\ n.trieman@fleet69. \\ demon.co.uk \\ BMJ 1999;319:13-6
}




\section{Design}

We aimed to detect changes over time, with a naturalistic longitudinal study design. We assigned patients to annual cohorts by year of discharge. Each patient was assessed at three time points: at baseline (before discharge), and at 1 year and 5 years after discharge. The clinical and social outcomes are described in detail elsewhere ${ }^{5-7}$ We assessed data pertaining to death, crime, vagrancy, readmission, and residential mobility.

We collected and constantly updated data by periodic visits to the residential settings, by phone calls to carers every 6 months, and by follow up interviews of each patient. We obtained supplementary information through hospital records and case notes and by contacting various agencies-for example, local social services and the NHS central register. The database for the Team for the Assessment of Psychiatric Services includes every admission to hospital, deaths, contact with police, and changes in place of residence.

We assessed the extent of restrictiveness of residential settings by the environmental index, which measures the number of rules and regulations and living conditions such as time of going to bed, personal space, and accessibility of amenities (scores are up to 50 ; the higher the score the greater the extent of restrictiveness). 5

\section{Results}

\section{Characteristics of patients}

The mean age of our study group (670 patients) was 54 years (range 19-97 years). Men were in the majority $(355 ; 52.9 \%)$. Only 40 patients $(5.9 \%)$ were married. Eighty $(11.9 \%)$ patients were from ethnic minorities. The median length of continuous stay in hospital was 28 years for patients from Claybury hospital and 21 years for patients from Friern hospital. New long stay patients constituted $39.1 \%$ of the sample (262 patients). Overall, 536 patients $(80.0 \%)$ had a primary diagnosis of schizophrenia. The overall level of functioning was low, ${ }^{2}$ with the least disabled patients selected for early discharge, leaving those who were more difficult to manage until last. ${ }^{38}$

\section{Follow up}

Over the 5 year follow up, 126 patients (18.8\%) died, 12 $(1.8 \%)$ moved away from London, and nine (1.3\%) could not be traced. The remaining 523 patients $(96.1 \%)$ were fully followed up.

\section{Residential mobility}

Overall, 525 patients (78.4\%) were initially resettled in staffed residential homes. Forty six patients (6.8\%) moved to unstaffed group homes, $72(10.8 \%)$ moved to independent flats, and only $27(4.0 \%)$ went to live with their families. The community homes offered residents more freedom than hospital wards, as shown by the difference in median scores for restrictiveness: 25 for hospital wards and 10 for community homes.

Of the 523 subjects who were fully followed up, 469 $(89.6 \%)$ were living in the community 5 years after they left hospital. Of these, $310(59.2 \%)$ were still in their original community placement.

\section{Readmission to hospital}

Over the 5 year follow up period, 201 patients were readmitted at least once to a psychiatric ward (38.4\% of all patients fully followed up); of these, 124 were admitted more than once. Of a total of 538 readmissions (of patients fully followed up), 160 (29.7\%) were long term (more than 6 months). At the 5 year follow up, 54 patients (10.3\% of the sample) were inpatients.

The likelihood of readmission, as analysed for the first six cohorts, was greater for young men, those with more previous admissions, and new long stay patients. ${ }^{9}$ The last two cohorts, discharged from hospital from 1991 to 1993, had the highest proportion of new long stay patients and also the highest readmission rate.

\section{Mortality}

Overall, 126 patients $(18.8 \%)$ died within 5 years of discharge - a crude death rate of 42.6 per 1000 person years $(95 \%$ confidence interval 35.3 to 50.0$)$. We calculated standardised mortality ratios using age specific death rates for the region's population for 1991 (the central year); these were 1.5 (1.1 to 1.9) for men and 1.9 (1.4 to 2.4) for women-both significantly above unity $(\mathrm{P}<0.01)$. Nine patients $(7 \%$ of all deaths) committed suicide, and cause of death was not determined in five patients (4\%).

\section{Crime}

All contacts with the police during the follow up period were recorded. Overall, there were 15 reported incidents of serious assault committed by 13 individuals; none had fatal consequences. Nine of these assaults were on members of the public, including three sexual assaults, one attempted murder, and two muggings. Three assaults were on fellow residents, and three assaults were directed at staff or police officers. There were also nine incidents of burglary, criminal damage, and lesser offences. At least three cases were associated with drug misuse.

Three patients offended more than once. One of those committed four serious crimes during the follow up period but managed to evade the judicial and mental health networks.

Of the 18 patients who committed crimes, four were admitted to secure units on police orders under the Mental Health Act, and 12 were sent to prison. Five of these 12 were later transferred to psychiatric wards.

\section{Vagrancy}

Nine patients could not be traced at the 5 year follow up. None of these were lost from staffed residential homes. Two patients were in prison before contact was lost. Three were listed in the NHS central register, and although they did not respond to their doctors' letters, they are not assumed to be vagrants. Three patients who lost contact with the local health and social services all had a history of vagrancy and probably became homeless owing to inadequate placement in bed and breakfast accommodation. Another patient who led a life of vagrancy was later retraced in hospital. Seven patients were temporarily lost during the 5 year follow up, but none had had transient periods of homelessness.

\section{Discussion}

Community care has been demonised by the media as causing homelessness, freeing dangerous people, and increasing the risks of self harm and suicide. Research evidence, mainly from the United States, claimed to 
establish such links. ${ }^{11}{ }^{11}$ The NHS, however, provides a more solid infrastructure than exists in the United States, and despite repeated administrative upheavals and financial constraints it has maintained a fundamental commitment to provide comprehensive care in the community.

In previous publications we reported positive changes in the quality of life of patients from Friern hospital and Claybury hospital after they were resettled in the community. ${ }^{6} 7$ We found that the patients' mental state and social behaviour remained stable, their daily living skills improved significantly, and their social life became enriched by more meaningful relationships. The majority of patients wanted to stay in their community homes. The only negative results were worsening immobility and incontinence-attributable to ageing rather than relocation.

\section{Residential care}

The core element in the resettlement programme was to provide alternative accommodation for every patient, construed as a home for life. This was achieved in full and was sustained. Most of the patients gained a stable and homelike place where their freedom was far less restricted. A comparatively small number of patients moved from their original placement as their needs or personal circumstances changed. We believe that accommodation should be secured unless the individual's needs become incompatible with the support on site.

\section{Homelessness}

Less than $1 \%$ of our sample drifted out of care and became homeless. Even this small problem might have been avoided if the patients had been placed in staffed accommodation rather than bed and breakfast hotels and homes with low support. We conclude that the increasing numbers of people living on streets in British cities cannot be attributed to the discharge of long stay psychiatric patients. Our findings are supported by surveys of homeless mentally ill patients, which show that only a few have had histories of prolonged psychiatric admissions. ${ }^{12}$

\section{Needs for inpatient care}

Although most patients, including dependent ones, could be managed successfully in the community, a considerable proportion of our sample required transient readmissions, thus creating a steady demand on local services for acute admissions. Risk factors affecting readmission to hospital were inherent-that is, depended on age, sex, diagnosis, and previous admissions-rather than variabes related to care. ${ }^{9}$ This implies that even with the best treatment and adequate support, patients with schizophrenia or other chronic illnesses are prone to exacerbation of symptoms that necessitate periodic admissions.

Our data indicate that $9-10$ beds are required for every 100 long stay patients discharged to the community, some of which should be in rehabilitation facilities. This need has not been accounted for in planning psychiatric services and is one factor contributing to the crisis affecting admission wards. ${ }^{13}$

A small yet important group of patients (about 15\% of Friern hospital's long stay population in 1985), regarded as unsuitable for community homes because
Key messages

- Replacing a psychiatric hospital with full residential facilities in the community has worked well for most long stay psychiatric patients

- Recurrent and sporadic readmissions to hospital are inevitable for high risk patients regardless of their living conditions

- Fears are unfounded that former hospital inmates are destined to neglect, high mortality, and homelessness, or that they pose a threat to the public

of aggressive or sexually provocative behaviour, was managed effectively in specialised facilities affiliated to general hospitals. ${ }^{4}$ Although many of these patients could eventually be discharged ( $\mathrm{N}$ Trieman and J Leff, personal communication), other community patients continued to accumulate in the admission wards to become new long stay patients. Therefore, long term inpatient care will still be needed when psychiatric institutions have closed.

\section{Crime}

Overall, $2 \%$ of our sample committed serious assaults over the 5 year follow up. Although this seems a small proportion, we were unable to compare with other cohort studies owing to methodological limitations such as selection bias and the distinction between offending and criminal conviction.

In the course of the reprovision programme, there was an attempt to screen out aggressive patients from placement in the community and to care for them in highly staffed facilities, but a few were missed. In retrospect, action should have been taken to contain those with a history of recidivism or coexisting misuse of drugs-misusing drugs is regarded as the most potent cause of criminal activity among young mentally ill patients. $^{14}$

\section{Mortality}

The patients' mortality rate, being excessive in relation to the general population, is consistent with rates quoted by a recent meta-analysis of studies on mortality in schizophrenic patients. ${ }^{15}$ Although the standardised mortality ratio for men in our sample was identical with that from the review, for unknown reasons the standardised mortality ratio for women was significantly higher than expected $\left(\beta^{2}=6.07, \mathrm{df}=1, \mathrm{P}<0.05\right)$.

We found no indication of higher suicide rates among patients living in the community. In fact the proportion of those who committed suicide was below the crude estimated risk of $22 \%$ of all deaths by suicide by the time that $20 \%$ of any cohort of followed up patients have died. ${ }^{16}$ The low suicide rate is mainly explained by the advanced stage of illness of most of our sample.

Despite local differences in demography and mental health policies, long stay populations in psychiatric hospitals are usually similar in composition. ${ }^{17}{ }^{18}$ The two samples of patients from Friern hospital and Claybury hospital were also remarkably similar on every measure made. ${ }^{2}$ Consequently, our findings could probably be generalised to completed and ongoing 
reprovision programmes in Britain, provided that these are well planned and well resourced.

\section{Conclusion}

Our findings dispel some of the common concerns and myths associated with "care in the community" patients and provide robust evidence that community care has worked well for the former patients of psychiatric hospitals, most of whom are currently living in the community and posing minimal risk to themselves and the public. In light of this, a change towards institutional care is not a rational policy.

We thank the research workers who have contributed to the collection of the data, the patients, and the hospital and community staff. This paper is designated the TAPS project 45.

Contributors: NT participated in data collection, analysis, interpretation, and drafting the paper. JL conceived and designed the Team for the Assessment of Psychiatric Services (TAPS) project and has been the director of the research team for the past 13 years. He helped to draft and edit this paper. GG participated in the analysis and interpretation of the mortality data. He also computerised the assessment tools used by TAPS. NT and JL will act as guarantors for the paper.

Funding: The Team for the Assessment of Psychiatric Services (TAPS) is funded by the Department of Health, North Thames Regional Health Authority, and the Gatsby Foundation. It is administered through the Department of Psychiatry and Behavioural Sciences, Royal Free and University College Medical School, London.

Competing interests: The TAPS project was largely funded by the Department of Health. This, and previous TAPS papers, were sent for comments to the Department of Health before submission. However, all papers, including this one, were drafted without administrative intervention or scrutiny of any kind. The opinions expressed do not necessarily reflect the policy of the Department of Health.

1 Weller MP. Mental illness-who cares? Nature 1989;339:249-52

2 O'Driscoll C, Wills W, Leff J, Margolius O. The TAPS project 10: the longstay populations of Friern and Claybury hospitals - the baseline survey. $\mathrm{Br}$ JPsychiatry 1993;162(suppl 19):30-5.

3 Trieman N, Leff J. The difficult to place patients in a psychiatric hospital closure programme. The TAPS project 24. Psychol Med 1996;26:765-74.

4 Trieman N, Leff J. The TAPS project 36: the most difficult to place longstay psychiatric inpatients: outcomes one year after relocation. $\mathrm{Br} J$ Psychiatry 1996;169:289-92

5 O'Driscoll C, Leff J. The TAPS project 8: design of the research study on the long-stay patients. Br J Psychiatry 1993;162(suppl 19):18-24

6 Leff J, Trieman N, Gooch C. The TAPS project 33: a prospective follow-up study of long-stay patients discharged from two psychiatric hospitals. Am J Psychiatry 1996:153:1318-24.

7 Leff J, Thornicroft G, Coxhead N, Crawford C. The TAPS project 22: a five year follow-up of long-stay psychiatric patients discharged to the community. Br J Psychiatry 1994;165(suppl 25):13-7.

8 Jones D. The TAPS project 11: the selection of patients for reprovision. $\mathrm{Br}$ J Psychiatry 1993;162(suppl 19):36-9.

9 Gooch C, Leff J. Factors affecting the success of community placement. The TAPS project 26. Psychol Med 1996;26:511-20.

10 Houghland G, Craig TM, Goodman AB. Mortality in the era of deinstitutionalization. Am J Psychiatry 1983;140:848-52.

11 Lamb HR. Lessons learned from deinstitutionalization in the US. $\mathrm{Br} J$ Psychiatry 1993;162:587-90.

12 Timms PW, Fry AH. Homelessness and mental illness. Health Trends 1989;21:70-1.

13 King's Fund Report. London's mental health. London: King's Fund, 1997.

14 Modestin J, Ammann R. Mental disorders and criminal behaviour. $\mathrm{Br}$ J Psychiatry 1995;166:667-75.

15 Harris EC, Baraclough B. Excess mortality of mental disorder. $\mathrm{Br} J$ Psychiatry 1998;173:11-53.

16 Hazel M, Inskip E, Harris C, Barraclough B. Lifetime risk of suicide for affective disorders, alcoholism and schizophrenia. $\mathrm{Br} J$ Psychiatry 1998;172:35-7.

17 Clifford P, Charman A, Webb Y, Best S. Planning for community care: long-stay populations of hospitals scheduled for rundown or closure. $\mathrm{BrJ}$ Psychiatry 1991:158:190-6.

18 Trieman N, Leff J. The TAPS project 42: the last to leave hospital-a profile of residual long-stay populations and plans for their resettlement. Acta Psychiatr Scand 1998;98:354-9.

(Accepted 30 March 1999)

\title{
Serious hazards of transfusion (SHOT) initiative: analysis of the first two annual reports
}

\author{
L M Williamson, S Lowe, E M Love, H Cohen, K Soldan, D B L McClelland, P Skacel, J A J Barbara
}

National Blood Service East Anglia/University of Cambridge Division of Transfusion Medicine, Cambridge CB2 2PT

L M Williamson, lecturer/consultant in transfusion medicine

National Blood

Service Manchester,

Manchester

M13 9LL

S Lowe,

SHOT assistant

national coordinator

E M Love,

consultant

haematologist

University College London Hospitals, London

WC1E 6DB

H Cohen,

consultant in

haematology

continued over

BMJ 1999;319:16-9

\author{
Abstract \\ Objective To receive and collate reports of death or \\ major complications of transfusion of blood or \\ components. \\ Design Haematologists were invited confidentially to \\ report deaths and major complications after blood \\ transfusion during October 1996 to September 1998. \\ Setting Hospitals in United Kingdom and Ireland. \\ Subjects Patients who died or experienced serious \\ complications, as defined below, associated with \\ transfusion of red cells, platelets, fresh frozen plasma, \\ or cryoprecipitate. \\ Main outcome measures Death, "wrong" blood \\ transfused to patient, acute and delayed transfusion \\ reactions, transfusion related acute lung injury, \\ transfusion associated graft versus host disease, \\ post-transfusion purpura, and infection transmitted \\ by transfusion. Circumstances relating to these cases \\ and relative frequency of complications. \\ Results Over 24 months, 366 cases were reported, of \\ which 191 (52\%) were "wrong blood to patient" \\ episodes. Analysis of these revealed multiple errors of \\ identification, often beginning when blood was \\ collected from the blood bank. There were 22 deaths
}

from all causes, including three from $\mathrm{ABO}$ incompatibility. There were 12 infections: four bacterial (one fatal), seven viral, and one fatal case of malaria. During the second 12 months, 164/424 hospitals (39\%) submitted a "nil to report" return. Conclusions Transfusion is now extremely safe, but vigilance is needed to ensure correct identification of blood and patient. Staff education should include awareness of $\mathrm{ABO}$ incompatibility and bacterial contamination as causes of life threatening reactions to blood.

\section{Introduction}

The current incidence of major complications due to blood transfusion is unknown. Until 1996 blood transfusion was not covered by either a confidential inquiry or the yellow card system of the Committee of Safety of Medicines. Perception of transfusion safety focuses on the diminishing risk of viral transmission, while the risk of $\mathrm{ABO}$ incompatible transfusion due to errors in blood or patient identification remains a threat. ${ }^{12}$ To analyse the residual risks of transfusion, a confidential voluntary reporting system for major transfusion events-serious hazards of transfusion (SHOT)- 